\title{
Dielectric relaxation of fulleroid materials filled PA6 composites and the study of its mechanical performance
}

\author{
Alex N. Sinitsin ${ }^{1}$, Vjacheslav V. Zuev ${ }^{1,2}$ \\ ${ }^{1}$ ITMO University, Kronverkskiy pr., 49, 197101 St. Petersburg, Russia \\ ${ }^{2}$ Institute of Macromolecular Compounds of the Russian Academy of Sciences, \\ Bolshoi pr. 31, 199004 St. Petersburg, Russia \\ lyubomirov85@mail.ru,zuev@hq.macro.ru
}

PACS 81.07.Lb

DOI 10.17586/2220-8054-2015-6-4-570-582

\begin{abstract}
The effect of fulleroid materials (fullerene $\mathrm{C}_{60}$ and fullerene soot which is used for fullerenes production) on the mechanical properties of polymer nanocomposites based on polyamide 6 (PA6) was investigated. Composites were synthesized by direct mixing in an extruder. Dielectric spectroscopy was used to investigate the influence of nanoparticles on relaxation processes in the polymer matrix. It is found that the segmental relaxation processes becomes faster with the addition of fullerene $\mathrm{C}_{60}$. In contrast, the secondary processes of PA6/fullerene $\mathrm{C}_{60}$ nanocomposites were observed to slow down with the addition of fullerene $\mathrm{C}_{60}$. This means that the local 'molecular stiffness' is increased, and a phenomenological link between the secondary relaxation times and the mechanical properties explains the increase in the Young's modulus of the nanocomposites upon the addition of $\mathrm{C}_{60}$. These observations suggest that nanoparticles can have a qualitatively different effect on the matrix polymer dynamics at different length scales, and caution must be taken in comparing the changes in the dynamics associated with different relaxation processes.
\end{abstract}

Keywords: composites; manufacturing; mechanical properties; fullerene $\mathrm{C}_{60}$; fullerene soot: dielectric spectroscopy.

Received: 2 March 2015

Revised: 18 April 2015

\section{Introduction}

Reinforcing thermoplastic polymers with nanoparticles to form nanocomposites is one means to increase the usage of polymeric materials. A number of polymers can be considered as competitive materials for tribological applications because of their low friction coefficients against steel counterparts, good damping properties, and self-lubricating ability. Among thermoplastic polymers, PA6 has become a strong competitor matrix owing to its good thermal stability, low dielectric constant and high tensile strength. PA6 has been reported to have a superior wear resistance sliding against a steel counterface relative to other polymers. In order to meet the special needs of tribological applications, polymer composites can be designed by selecting the correct composition and choosing an appropriate manufacturing process. The improvement of mechanical and/or tribological properties of polymers by incorporation of particulate filler materials has been widely studied [1]. Under extreme friction conditions, however, conventional polymer composites usually are not effective for antiwear and friction reduction; for example, under heavy load. Nanoparticle-reinforced polymer composites are the most rapidly growing class of materials due to a good combination of high strength and modulus at very low level of loading [2]. Nanocomposites are compatible with conventional polymer processing, thus avoiding the costly lay up required for the fabrication of conventional fiber-reinforced composites. When the fillers' sizes are on the order of nanometers, even small a concentration can 
lead to enhancements in properties unprecedented in conventional composites [3]. The unique properties of polymer nanocomposites are attributed to the high filler surface area-to-volume ratio, which results in significant interfacial contact areas between the polymer and the particles. The large interfacial contact areas enable a substantial fraction of polymer segments to interact directly with the filler particles, even at low particle concentrations.

Polymer/ fullerene $\mathrm{C}_{60}$ blends are an ideal system to study polymer-nanoparticles interactions since fullerene $\mathrm{C}_{60}$ is monodisperse, available in high purity, and dispersible in many polymer and block copolymers [4]. The most challenging problem in the fabrication of polymer nanocomposites is dispersing the nanofillers in the polymer matrix [5]. Nanofillers strongly self-associate into ropes and other high-ordered structures which are extremely difficult to disperse in polymers. As result, the mechanical properties of polymer nanocomposites can be very far from that which was predicted [6]. Here, we use broadband dielectric spectroscopy (BDS) to directly measure the influence of fullerene $\mathrm{C}_{60}$ on the polymer relaxations corresponding to different lengths and time scales. BDS is one of the most efficient tools for studying the molecular relaxations of polymers. It covers a broad frequency range, allowing measurement of different relaxation processes simultaneously, and even entire chain relaxation processes under favorable circumstances [7].

We studied the influence of fullerene $C_{60}$ or fullerene $C_{60}$ containing materials on the mechanical properties of PA6 based composites. In this paper, we report the data obtained from BDS measurements.

\section{Experimental}

\subsection{Material and manufacturing}

Fullerene $\mathrm{C}_{60}$ (purity 99.9\%), and fullerene soot, containing about $10.5 \%$ fullerenes, which was supplied by ZAO ILIP (Russia), were used as fillers. The fullerene soot used is an ultra dispersed carbon formed by a voltaic arc of graphite in an inert gas atmosphere during fullerene production, with particle diameters of $0.5-2.0 \mu \mathrm{m}$. Plasticizer ARMOSIL E®) (AKZO NOBEL, (amide of oleic acid)) was added to the $1 \% \mathrm{C}_{60}$ samples to aid the $\mathrm{C}_{60}$ dispersion.

The granules of PA6 (Volgamid@ 32, OAO Kuibishevasot, Russia, here after B32, density $1.14 \mathrm{~g} / \mathrm{cm}^{3}$ ) were used for the preparation of nanocomposites. We used a $\mathrm{C}_{60}$ solution in o-xylene as the means for impregnating the granules with a calculated amount of fullerene. The fullerene soot was premixed with calculated amounts of PA6 granules for $5 \mathrm{~min}$ in a high-speed powder mixer. After that, the granules were dried for $5 \mathrm{~h}$ at $80{ }^{\circ} \mathrm{C}$. The composite preparation was carried out in a single screw extruder (Haake Rheocord, Germany) at a screw speed of $50 \mathrm{rpm}$. Plasticizer ARMOSIL Eß (AKZO NOBEL, (amide of oleic acid)) was added to the PA6 granules with $1 \% \mathrm{C}_{60}$ to aid the best $\mathrm{C}_{60}$ dispersion. The temperature setting from the hopper to the die was $220 / 225 / 230 / 235{ }^{\circ} \mathrm{C}$. During melt extrusion, ventilation was kept on to remove trapped air in materials. After pelletizing, the nanocomposite granules were dried for $5 \mathrm{~h}$ at $80{ }^{\circ} \mathrm{C}$. Dried pellets were injected-molded (KM-160E injecting molding machine, KraussMaffei, Germany) into standard test species. The temperature profile setting from hopper to nozzle ranged from $200-215{ }^{\circ} \mathrm{C}$ and the mold temperature was kept at $25^{\circ} \mathrm{C}$. The holding pressure and screw rotation speed were 300 bar and $100 \mathrm{rpm}$ respectively with throughput of $50 \mathrm{~cm}^{3} / \mathrm{s}$. As a reference, neat PA6 was also similarly extruded and injectedmolded. For dielectric measurements, nanocomposite pellets were placed and melted in a parallel-plate capacitor with $20 \mathrm{~mm}$ diameter; a pair of glass fiber with $80 \mu \mathrm{m}$ diameter was used as the spacer between electrodes. 


\subsection{Mechanical properties}

Tensile properties were measured in the accordance with ISO 527. Tests were conducted using $6 \times 6 \times 40 \mathrm{~mm}^{3}$ specimens for tensile strength and Young's modulus estimation on a UTS 10 devise (UTS Test System, Germany) at an elongation rate of $2 \mathrm{~mm} / \mathrm{min}$. No less than 5 specimens were taken for each sample to obtain an average value. Shore $D$ hardness test of composites were performed according to the ASTM 2240 using a Zwick/Roell Test stand 7206.200 machine. To increases the accuracy of measurement, all samples' surfaces were well polished using high-grade sandpaper prior to test. An average hardness was calculated by 10 indentation measurements.

\subsection{Microscopy}

An optical microscope, Micromed Met 400 (Micromed Met, Russia), with magnification up to $400 \times$, was used to analyze the worn surfaces of the composites. Scanning electron microscopy (SEM) images were obtained with Zeiss ULTRAplus FEG-SEM instrument with magnification $2.000-30.000 \times$.

\subsection{Thermal properties}

Differential scanning calorimetry (DSC) measurements were performed using a Netzsch DSC 204F1 instrument at a scan rate $10 \mathrm{~K} / \mathrm{min}$. The thermal gravimetric analysis (TGA) measurements were performed in an inert $\mathrm{N}_{2}$ atmosphere and an oxygenated atmosphere on a NTZSCH TG $209 \mathrm{~F} 1$ instrument with $\mathrm{Al}_{2} \mathrm{O}_{3}$ pan using $2-3 \mathrm{mg}$ of nanocomposite as probe. The samples were heated $30-800{ }^{\circ} \mathrm{C}$ and the temperature was raised at the rate of $10 \mathrm{~K} / \mathrm{min}$.

\subsection{Dielectric spectroscopy}

Measurements were performed with an Alpha Analyzer combined with a Quatro Temperature Control system unit that provides temperature stability of $0.1{ }^{\circ} \mathrm{C}$, both by Novocontrol. Complex dielectric permittivity $\varepsilon^{*}(f)=\varepsilon^{\prime}(f)-i \varepsilon^{\prime \prime}(f)$ was measured isothermally in steps of $5{ }^{\circ} \mathrm{C}$ over the temperature interval -150 to $+200{ }^{\circ} \mathrm{C}$ and frequency range from $10^{-2}$ to $10^{6} \mathrm{~Hz}$. Nanocomposite films were placed and melt in parallel-plate copper capacitor with $20 \mathrm{~mm}$ diameter, and a pair of glass fiber with $50 \mu \mathrm{m}$ diameter was used as the spacers between electrodes.

\section{Results and discussion}

\subsection{Preparation of nanocomposites}

The reinforcement effect in nanocomposites is very sensitive to the quality of the nanoparticle dispersion [5]. Fabrication methods are overwhelmingly focused on improving nanofiller dispersion because better filler distribution in the polymer matrices has been found to improve the nanocomposites' properties. In-situ polymerization is generally more effective than other potential methods in dispersing nanofillers in a polymer matrix due to the high viscosities of polymeric solutions and melts. Furthermore, in-situ polymerization methods enable covalent bonding between the nanofillers and the polymer matrix by using various reactions to promote compatibilization as was shown by us previously [8]. Conversely, mixing in an extruder is a more acceptable industrial method for the preparation of polymer composites. This stimulated us to use this method as a fabrication technique for the synthesis of PA6/fulleroid material nanocomposites.

As an initial level of analysis, the dispersion state of fullerene $\mathrm{C}_{60}$ can be evaluated by the polymer nanocomposite's color. It is well known, that if fullerene $C_{60}$ is semicrystalline 
or aggregated in a polymer matrix, the nanocomposite has a brownish color, while when it is well dispersed in polystyrene the color is purple, or orange when in polymethylmethacrylate (PMMA) [9]. We used a fullerene $\mathrm{C}_{60}$ solution in o-xylene as the means of impregnating the granules with a calculated amount of the fullerene $C_{60}$ because this pathway gives much better results than pulverization [10]. As a result, the samples containing $0.01 \mathrm{wt} . \%$ of fullerene $\mathrm{C}_{60}$ after injecting molding were light cream colored. In the SEM images of these samples, one can not find any aggregates of fullerene $\mathrm{C}_{60}$. However, it is well known that the results of the scattering methods regarding dispersion of nanofillers in polymers are difficult to interpret because of the low contrast, and because the precise rigid-rod behavior $\left(I \propto Q^{-1}\right)$ is not equivalent to good dispersion at all length scales [11]. Hence, the light cream color of the nanocomposites may give evidence that the fullerene $\mathrm{C}_{60}$ dispersion is not on the molecular level.

A similar way of preparing nanocomposites with 1 wt.\% of fullerene $\mathrm{C}_{60}$ leads to aggregation of nanofillers in the polymer matrix, as seen from the SEM images. To solve this problem, we have added a plasticizer (ARMOSIL E, at $0.05 \mathrm{wt} . \%$ ) to the composition. The decrease in viscosity of the polymer melt allows for better dispersion of the filler and the resulting nanocomposite after injection molding was light cream colored (similar to the composite with 0.01 wt. $\%$ of fullerene $\mathrm{C}_{60}$ ). The SEM images of these samples also did not show any aggregates of fullerene $\mathrm{C}_{60}$ (Fig. 1).

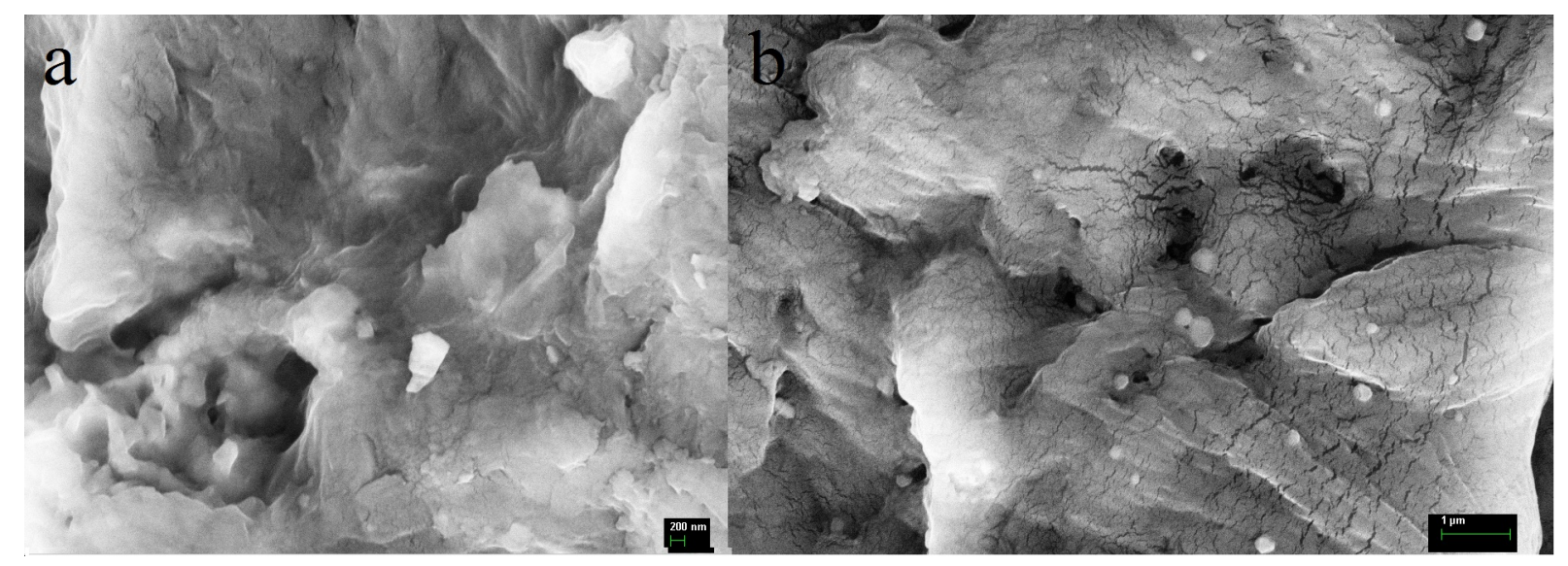

FIG. 1. SEM micrographs $(\times 30 \mathrm{k})$ of polymer nanocomposites: (a) with $1 \mathrm{wt} . \%$ of fullerene $\mathrm{C}_{60}$ and 0.05 wt.\% of ARMOSIL E; (b) with 1 wt.\% of fullerene soot

The similarity of the quality of fullerene $\mathrm{C}_{60}$ dispersion in both composites (with 0.01 and 1 wt. $\%$ of fullerene $\mathrm{C}_{60}$ ) is supported by DSC measurements. The melting temperatures of neat PA6 and the composites are nearly identical (Table 1).

To estimate the crystallinity of the samples, a value of $190.6 \mathrm{~J} / \mathrm{g}$ was used for the melting enthalpy of $100 \%$ crystalline PA6 [12]. The degree of crystallinity, $\chi$, was calculated from the areas of the corresponding DSC melting peaks according to $\chi=H_{m} / \Delta H_{100}$, where $\chi$ is degree of crystallinity, $\Delta H_{m}$ is the peak area of the consideration, and $\Delta H_{100}$ is the heat of fusion of $100 \%$ crystalline PA6. We have found that the crystallinity of nanocomposites is increased in comparison with neat PA6 (from $22 \%$ to $26-27 \%$ ), independently of the fullerene $\mathrm{C}_{60}$ content (for nanocomposite with $1 \mathrm{wt} . \%$ of fullerene $\mathrm{C}_{60}$ this amount should be subtracted from the total mass of the composite), allowing us to neglect any differences in the fullerene $\mathrm{C}_{60}$ dispersion quality in both nanocomposites. A micrograph of the PA6 nanocomposite surface filled with fullerene soot (Fig. 1) demonstrates that no segregation of soot particles is observed and that 
TABLE 1. Molten behavior of neat PA6 and nanocomposites

\begin{tabular}{cccc}
\hline Loading, wt. $\%$ & $T_{m}\left({ }^{\circ} \mathrm{C}\right)$ & $\Delta H, \mathrm{~J} / \mathrm{g}$ & Crystallinity, \% \\
\hline B32 & 221 & 42.3 & 22 \\
Fullerene & $\mathrm{C}_{60}$ & & \\
0.01 & 221 & 51.0 & 27 \\
$1^{a}$ & 220 & 48.1 & 25 \\
Fullerene & Soot & \\
1 & 221 & 45.4 & 24 \\
\hline \multicolumn{4}{c}{0.05 wt.\% of ARMOSIL E (AKZO NOBEL) }
\end{tabular}

they are randomly distributed in the polymer matrix. This is favorable for achieving greater matrix stiffness and consequently increases the toughening efficiency.

Thus, we see that our method for preparing the PA6/fulleroid materials is free from filler aggregation, thus allowing us to investigate the influence of pristine fulleroid filler (with no ropes and other high-ordered structures) on the properties of nanocomposites.

\subsection{Mechanical properties}

The main improvement in mechanical properties of nanocomposites relates to the large increase in modulus. Usually, an increase in the modulus of approximately $10 \%$ per wt. $\%$ filler has been observed in both in situ polymerized and melt processed PA6 nanocomposites [13]. Such an increase is too small for nanofillers which are used with much lower loadings. In our previous work, both the tensile modulus and tensile strength of in situ-polymerized PA6 composites were improved by up to $15 \%$ with a loading of $0.01 \mathrm{wt} . \%$ fullerene $\mathrm{C}_{60}$. The tensile mechanical properties of composites under study are summarized in Table 2.

TABLE 2. Effect of loading on the mechanical properties of the polymer nanocomposites

\begin{tabular}{|c|c|c|c|c|c|c|}
\hline $\begin{array}{c}\text { Loading, } \\
\text { wt. } \%\end{array}$ & $\begin{array}{l}\text { Young's } \\
\text { modulus } \\
(\mathrm{E}), \mathrm{GPa}\end{array}$ & $\begin{array}{l}\text { Tensile } \\
\text { strength } \\
\sigma, \mathrm{MPa}\end{array}$ & $\begin{array}{c}\text { Elongation } \\
\quad \varepsilon, \%\end{array}$ & $\begin{array}{c}\text { Hardness } \\
\text { Shore } D \\
\text { (H) }\end{array}$ & $\begin{array}{l}\text { Rigidity } \\
(E / H) \\
\times 10^{-3}\end{array}$ & $\begin{array}{l}\text { Resistance } \\
\text { to plastic } \\
\text { deformation } \\
\left(H^{3} / E^{2}\right) \times 10^{5}\end{array}$ \\
\hline B32 & $0.693 \pm 0.017$ & $63 \pm 1$ & $290 \pm 6$ & 72.18 & 9.60 & 7.83 \\
\hline Fullerene & $\mathrm{C}_{60}$ & & & & & \\
\hline 0.01 & $0.714 \pm 0.022$ & $65 \pm 1$ & $301 \pm 6$ & 73.35 & 9.73 & 7.74 \\
\hline $1^{a}$ & $0.265 \pm 0.037$ & $11 \pm 1$ & $287 \pm 2$ & 48.93 & 5.42 & 1.65 \\
\hline Fullerene & Soot & & & & & \\
\hline 1 & $0.622 \pm 0.045$ & $62 \pm 1$ & $286 \pm 14$ & 73.06 & 8.51 & 10.15 \\
\hline
\end{tabular}

Table 2 shows that the Young's modulus, the tensile strength and elongation of the melt processed nanocomposite increase slightly at this filler loading. Furthermore, all of these parameters decrease significantly with an increase in the filler concentration. This is mainly attributed to the carbon particles aggregating easily as the filler concentration is increased. Additionally, the sample with $1 \%$ of fullerene $\mathrm{C}_{60}$ also contained ARMOSLIP E $(0.05 \%)$ which acted as a plasticizer. The difference in the properties of neat PA6 synthesized by us [8] and commercial 32 used as the choice of polymer for extrusion can be related to effect of reprocessing [14]. 
The possibility of degradation is of clear importance here, since two mixing cycles are needed to produce these materials. For nanocomposites, besides the possible degradation processes associated with the matrix, additional degradation processes due to the presence of nanoparticles can occur. These processes can lead to additional degradation of the matrix induced by the presence of nanoparticles, as the latter can act as a catalyst; degradation by modification of the polymer/filler interface or degradation by collapsing and agglomeration of the nanoparticles. If any of the above processes take place to a significant extent, they would influence the mechanical properties. In our case the first two possibilities are excluded because the fullerene $\mathrm{C}_{60}$ prevents all free-radical degradation processes of polymers, including mechanodestruction. This was supported by the data of TGA measurements (Fig. 2). As one can see, the TGA curves for neat B32 and all nanocomposites are identical.

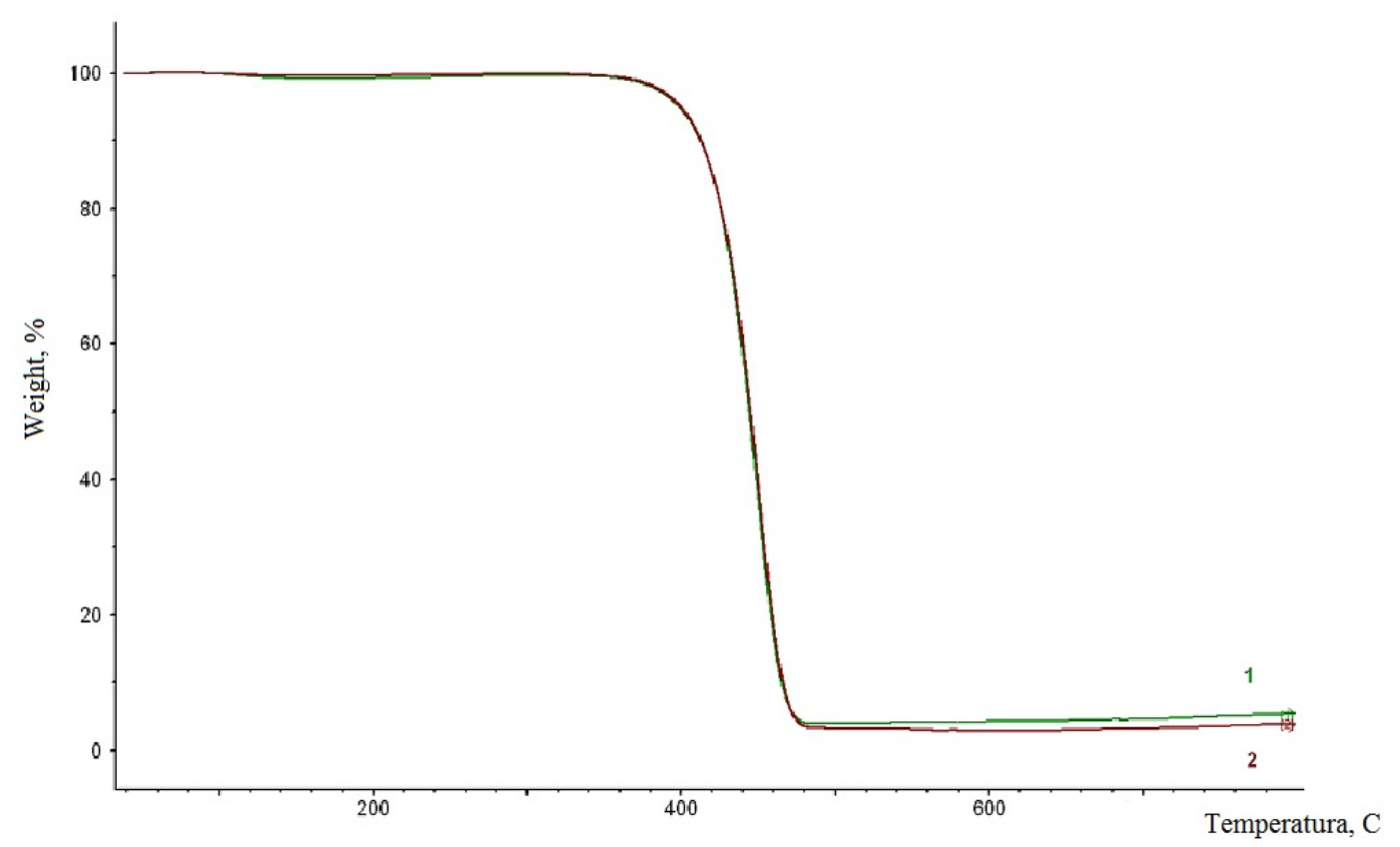

FIG. 2. TGA curve of neat PA6 (1); and with $1 \mathrm{wt} . \%$ of fullerene soot (2)

As can be seen from Table 2, the hardness of nanocomposites (without adding the plasticizer) increased slightly in comparison to neat PA6, which can be connected with increased crystallinity. According to conventional fracture mechanics theory, the ratio of the Young's modulus and hardness $\left(E / H\right.$ ratio) represents the rigidity of a material and the ratio $H^{3} / E^{2}$ represents the resistance to plastic deformation. Hence, the nanocomposite with $0.01 \mathrm{wt} \%$ of fullerene $\mathrm{C}_{60}$ added was found to be highly rigid and tough. Such spectacular increase of the overall stiffness is generally reported upon the addition of very low fractions of nanofillers (e.g., clay or phyllosilicates [15]). This remarkable improvement in mechanical properties in regard to the neat PA6, compared to conventional polymer composites with similar filler content, is attributed to the high specific area of the nanoparticles, and therefore, to the strong interactions with polymer macromolecules [16]. PA6 is a crystalline thermoplastic polymer and its crystalline structure can involve different forms which coexist in different amounts depending on the processing conditions and additives. PA6 usually crystallizes into two forms: $\alpha$ and $\gamma$ [17]. Although the $\alpha$ and $\gamma$-forms are thermally stable, the addition of nanopatricles can induce a crystal transformation from the $\alpha$-form to the $\gamma$-form and inversely, that has 
been well documented using DSC, FTIR, XRD, and NMR measurements [18]. The PA6 $\alpha$ phase crystals were reported to exhibit a higher modulus than those of the $\gamma$-phase [19]. This could be one of the reasons for the enhanced properties observed in PA6 composites reinforced with various materials. The fullerene $C_{60}$ [8] or fullerene $C_{60}$-like inorganic fillers [13] have an $\alpha$-nucleation effect on the PA6-matrix upon in situ polymerization. It was manifested as ground for reinforcing mechanism of such types of nanocomposites [20]. The thermal properties of the composites were investigated by DSC. However, fullerene $\mathrm{C}_{60}$ does not change the crystallization behavior of PA6 nanocomposites prepared by the extrusion method. Only the $\alpha$-form crystalline phase was found in B32 and the nanocomposites prepared by us. Therefore, there should be other reinforcing mechanisms. Essentially these mechanisms should involve active interactions between the fullerene $\mathrm{C}_{60}$ and PA6 chains.

Here, we use BDS to measure directly the influence of fullerene $\mathrm{C}_{60}$ on the polymer relaxations corresponding to different lengths and time scales.

\subsection{Dielectric spectroscopy}

Complex dielectric permittivity $\varepsilon^{*}$ was measured over wide frequency and temperature ranges. Fig. 3 is an isochronal graph of the dielectric loss of the B32 and nanocomposites as a function of temperature.

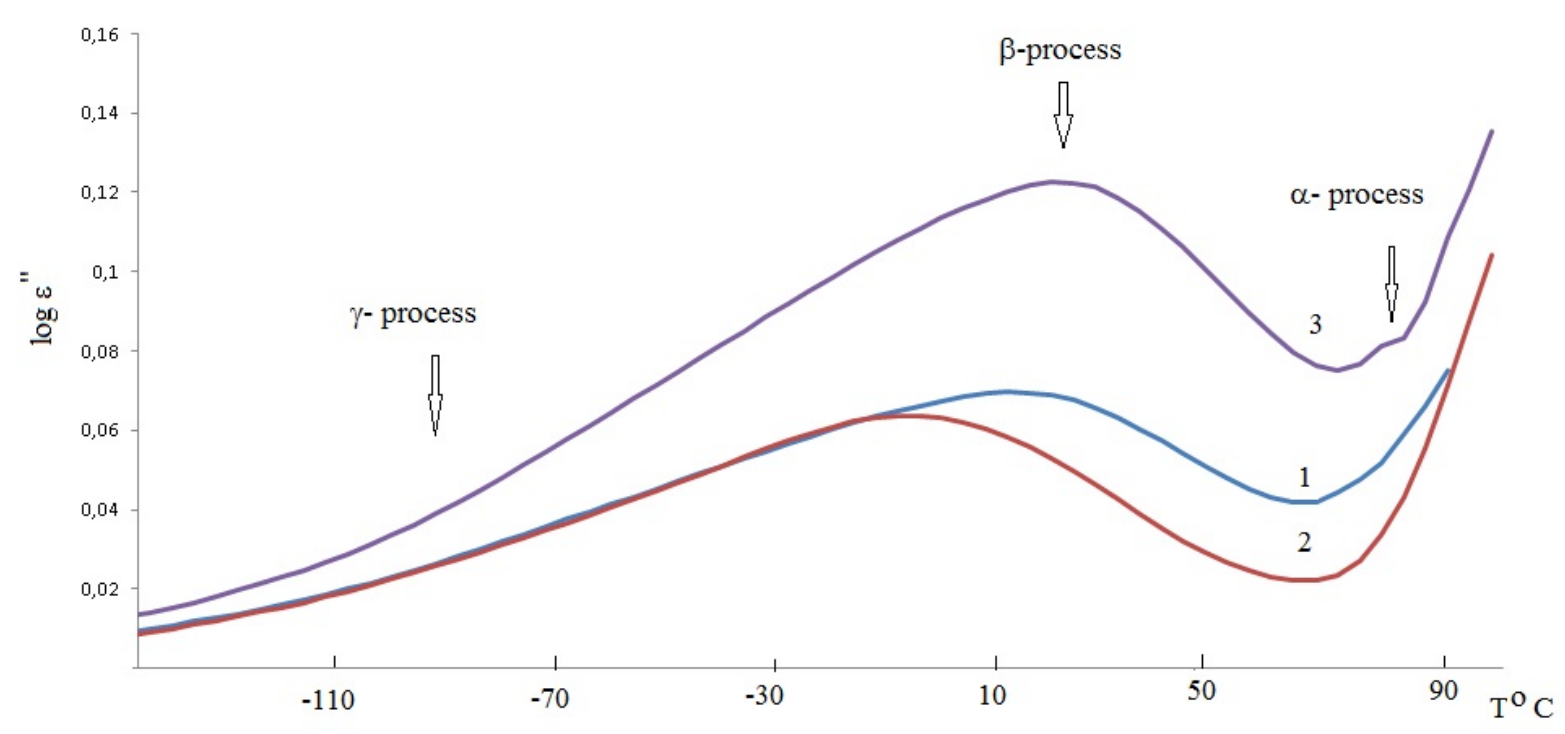

FIG. 3. Temperature dependence of imaginary part of the dielectric permittivity for neat PA6 (1); with 0.01 wt.\% of fullerene $\mathrm{C}_{60}$ (2); with $1 \mathrm{wt} . \%$ of fullerene soot (3) at $1 \mathrm{~Hz}$

Three relaxations can be identified in all samples. They were identified and reported for the pure PA6 [21-24]. In the present work, the effect of water on the relaxation processes is considered to be negligible, due to the initial drying of the materials prior to testing. If any small amounts of water remained in the samples, it was firmly bound water. Additionally, similar amounts of bound water should be present in all tested samples, thereby making direct comparison of the results possible. 
The main characteristic of each relaxation process is the most probable relaxation time, $\tau_{\max }$, determined according to [25] as:

$$
\tau_{\max }=\tau_{H N}\left(\frac{\sin \left(\frac{\pi \alpha \beta}{2(\beta+1)}\right)}{\sin \left(\frac{\pi \alpha}{2(\beta+1)}\right)}\right)^{\frac{1}{\alpha}}
$$

Based on the previous experience, a model function has been fitted to the dielectric data, with the Havriliak - Negami (N-H) phenomenological relation [26]:

$$
\varepsilon^{*}(\omega)=\varepsilon_{\infty}+\frac{\Delta \varepsilon}{\left(1+\left(i \omega \tau_{N H}\right)^{1-\alpha}\right)^{\beta}}
$$

being the most general form. In this expression, $\varepsilon^{*}=\varepsilon^{\prime}-i \varepsilon^{\prime \prime}$, is the complex dielectric function, $\omega=2 \pi f, f$ is the field frequency, $\Delta \varepsilon$ is the intensity of the dielectric process, $\tau_{N H}=1 / 2 \pi f_{N H}$ and $f_{N H}$ is the position of the relaxation process on the frequency scale, $\varepsilon_{\infty}$ is $\varepsilon^{\prime}(f)$ for $f \gg f_{N H}, \alpha$ and $\beta$ are shape parameters representing the symmetrical and asymmetrical broadening of the relaxation with respect to the Debye peak. Fig. 4 displays the fits obtained when one $\mathrm{NH}$ term is used to fit the relaxation spectrum obtained for the nanocomposite with $0.01 \mathrm{wt} . \%$ of fullerene $\mathrm{C}_{60}$ at $223 \mathrm{~K}$. The quality of the fit is quite good and the characteristic relaxation time for each relaxation process (Fig. 4a shows $\gamma$-relaxation and $\beta$-relaxation) can be extracted.
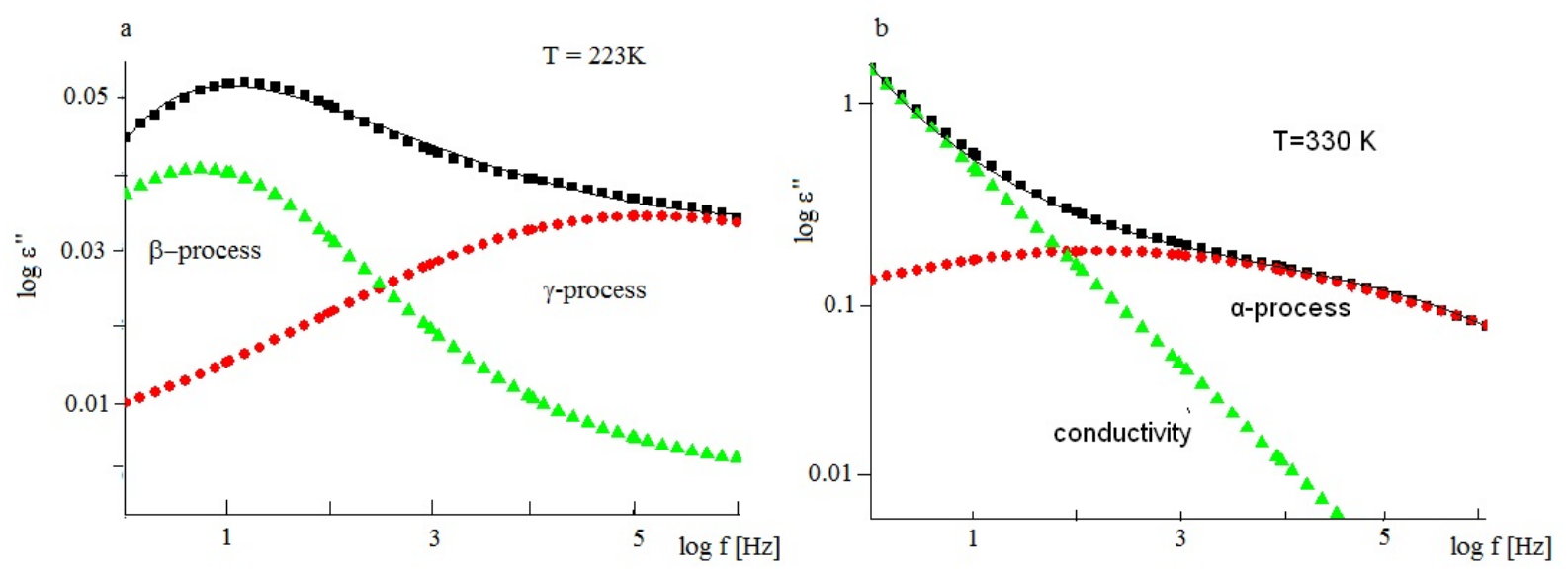

FIG. 4. Decomposition in N-H distributions of the isothermal runs of imaginary part of the dielectric permittivity for nanocomposite with $0.01 \mathrm{wt} . \%$ of fullerene $\mathrm{C}_{60}$ sample (a) and with $1 \mathrm{wt} . \%$ and of fullerene $\mathrm{C}_{60}$ and $0.05 \mathrm{wt} . \%$ of ARMOSIL $\mathrm{E}(\mathrm{b}):(\boldsymbol{\square})$ is experimental points; solid line is sum of calculated profiles

The $\gamma$ - and $\beta$-relaxations are due to relatively shorter chain motions. The dependences of $-\log \tau_{\max }$ on the inverse temperature are linear for all nanocomposites and neat B32 in the regions of $\gamma$ and $\beta$ processes (Fig. 5). As a result, the temperature dependence of these relaxations can be modeled by an Arrhenius type expression (Eq. 3) [27]:

$$
\tau(T)_{\max }=\tau_{0} \exp \left(\frac{E_{a}}{R T}\right) .
$$

Here, $\tau_{0}=\tau_{\max }$ at $T \rightarrow \infty, E_{a}$ is the activation energy. Values of $\tau_{0}$ and $E_{a}$ are given in Table 3. 

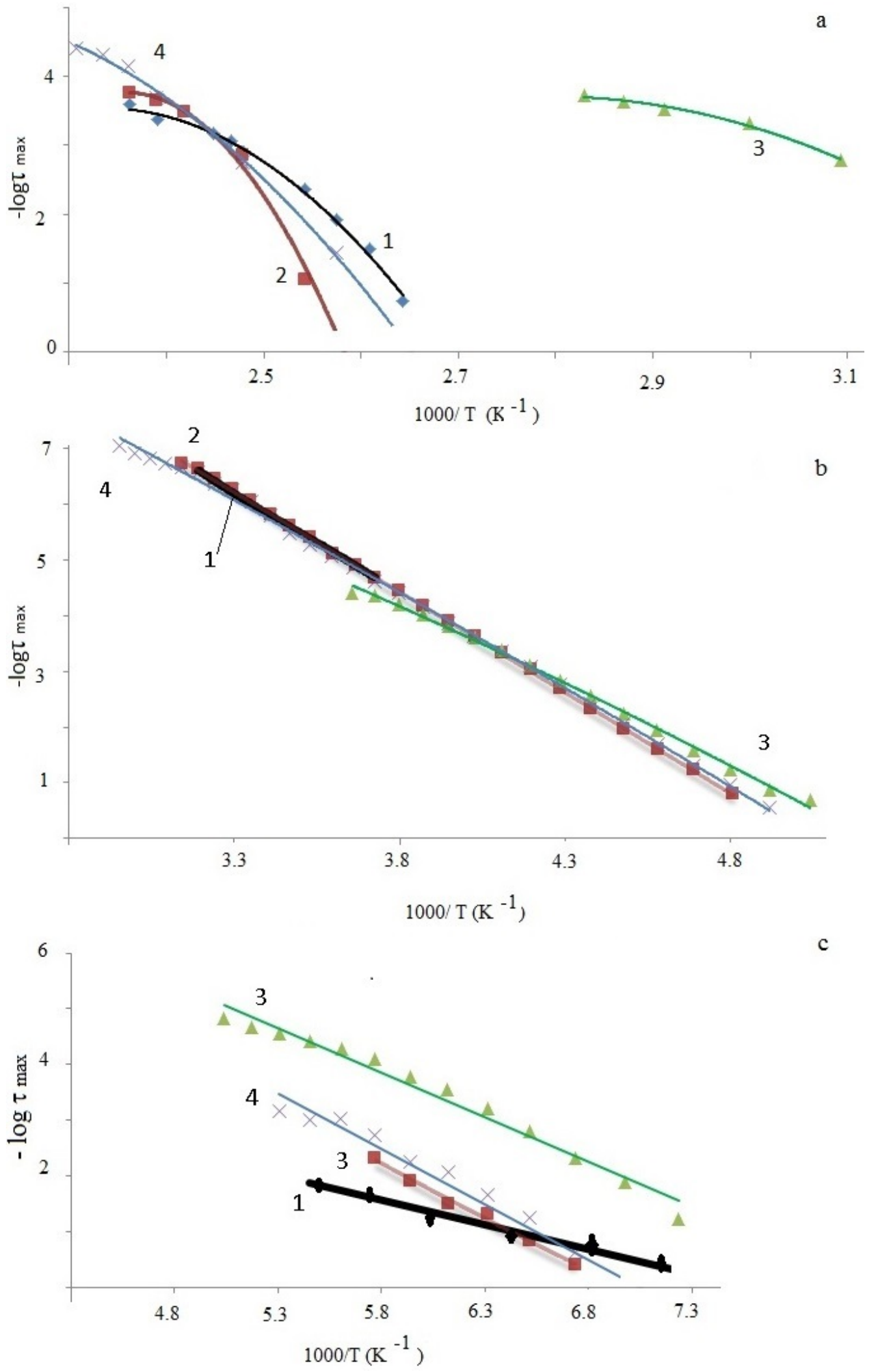

FIG. 5. Dependences of $-\log \tau_{\max }$ on repciprocal temperature for neat PA6 (1) and nanocomposites with 0.01 wt. $\%$ of fullerene $\mathrm{C}_{60}(2)$; with $1 \mathrm{wt} . \%$ and of fullerene $\mathrm{C}_{60}$ and 0.05 wt.\% of ARMOSIL E (3); with 1 wt. $\%$ of fullerene soot (4); a: $\alpha$-relaxation process; b: $\beta$-relaxation process; c: $\gamma$-relaxation process 
TABLE 3. $T_{g}$ and parameters of $\gamma, \beta$ and $\alpha$ (from VFT fit) relaxation processes of neat PA6 and nanocomposites

\begin{tabular}{|c|c|c|c|c|c|c|}
\hline $\begin{array}{c}\text { Loading, } \\
\text { wt. } \%\end{array}$ & $\begin{array}{c}E_{a} \\
\mathrm{kcal} / \mathrm{mol}\end{array}$ & $\tau_{0}, \mathrm{~s}$ & $\begin{array}{c}E_{\mathrm{VFT}}, \\
\mathrm{kcal} / \mathrm{mol}\end{array}$ & $D$ & $T_{0}, \mathrm{~K}$ & $T_{g}, \mathrm{~K}$ \\
\hline B32 & & & & & & \\
\hline$\gamma$-mode & 6.43 & $1 \times 10^{-11}$ & 2.58 & & & \\
\hline$\beta$-mode & 15.65 & $1 \times 10^{-17}$ & & & & \\
\hline$\alpha$-mode & & $1.9 \times 10^{-7}$ & & 1.18 & 260 & 360 \\
\hline Fullerene & $0.01 \% \mathrm{C}_{60}$ & & & & & \\
\hline$\gamma$-mode & 8.79 & $1 \times 10^{-13}$ & & & & \\
\hline$\beta$-mode & 16.59 & $1 \times 10^{-18}$ & & & & \\
\hline $\begin{array}{c}\alpha \text {-mode } \\
1 \%{ }^{a}\end{array}$ & & $5.9 \times 10^{-6}$ & 2.59 & 1.14 & 260 & 360 \\
\hline$\gamma$-mode & 7.39 & $1 \times 10^{-13}$ & & & & \\
\hline$\beta$-mode & 13.25 & $1 \times 10^{-15}$ & & & & \\
\hline$\alpha$-mode & & $4.5 \times 10^{-5}$ & 3.42 & 1.55 & 261 & 335 \\
\hline Fullerene & Soot 1\% & & & & & \\
\hline$\gamma$-mode & 9.19 & $1 \times 10^{-14}$ & & & & \\
\hline$\beta$-mode & 15.63 & $1 \times 10^{-17}$ & & & & \\
\hline$\alpha$-mode & & $7.6 \times 10^{-9}$ & 2.65 & 5.02 & 260 & 360 \\
\hline
\end{tabular}

The $\beta$-relaxation is phenomenologically linked to the mechanical properties of polymeric materials [28,29]. From Table 3, one can see that symbatic changes of $E_{a}$ and Young's modulus for the composites shows that the presence of fullerene hampers the molecular motions in the composites, leading to hardening of the polymer chains and impeding secondary relaxation processes. This explains the increase in Young's modulus for the nanocomposites. Assignment of molecular motions associated with the $\beta$-relaxation is complicated and a number of varying opinions exist in the literature [21-24]. However, these motions should be connected with the motion of amide groups together with neighboring methylene groups, and size of this moving unit is comparable to the size of the fullerene $\mathrm{C}_{60}$ molecule. This can explain the hampering of $\beta$-relaxation upon introduction of such fillers.

The low temperature $\gamma$-relaxation involves the motion of short sequences of $\mathrm{CH}_{2}$ groups connected with an amide group which provides the dielectric activity. As a result, the dependence of $E_{a}$ of the $\gamma$-relaxation on the amount of nanofiller is quite. The tightly bound fullerene molecules create inter-chain bonds between the neighboring carbonyl groups, thus increasing the energy necessary to reorient the dipolar entities whose motion causes the $\gamma$ process. The introduction of the plasticizer slightly blurs this dependence.

It is well known that the $\beta$ process is related to the toughness of the polymer [25]. The nanocomposite with $1 \mathrm{wt} . \%$ of fullerene soot was found to be both rigid and tough (Table 2). There was a demonstrated decrease in the activation energy of the $\beta$ process compared to that of the nanocomposite with $0.01 \mathrm{wt} . \%$ of fullerene $\mathrm{C}_{60}$. This indicated that carbon nanoparticles can significantly improve the energy dissipation process in the polyamide matrix. This process can lead to domination of the plastic deformation mechanism in the composite that effectively blunts 
the crack trip. Hence, the suggested mechanism could be a major reason for the higher values of the resistance to plastic deformation. This mechanism is applicable to both semicrystalline and amorphous systems and is typically absent in conventional polymer composites. The decrease in the activation energy of the $\beta$ relaxation process indicates that the mobility of polymer matrix is a pre-condition for this mechanism to be effective. In other words, the increase in toughness is proportional to the increase in the local mobility of the polymer chains, which in turn determines the nanoparticle mobility.

The $\alpha$-relaxation (the highest temperature relaxation in Fig. 3) is connected with onset of large-scale motions of chain segments in the vicinity of $T_{g}$. At higher temperatures near the $\alpha$ relaxation process, heating is accompanied by creation of carriers due to ionization of impurities and the breaking of chemical bonds (e.g., the N-H bonds, etc.). Hence, it is necessary to add an additional term connected with conductivity in Eq. (2):

$$
\varepsilon^{*}(\omega)=\varepsilon_{\infty}+\frac{\Delta \varepsilon}{\left(1+\left(i \omega \tau_{N H}\right)^{1-\alpha}\right)^{\beta}}-i\left(\frac{\sigma_{0}}{\omega \varepsilon_{0}}\right) .
$$

In this equation, $\sigma_{0}$ is dc conductivity and $\varepsilon_{0}$ is the permittivity of free space $(8.854 \mathrm{pF} / \mathrm{m})$. Fig. $4 \mathrm{~b}$ displays the fits obtained when two such N-H terms are used to fit relaxation spectrum obtained for the nanocomposite with $0.01 \mathrm{wt} . \%$ of fullerene $\mathrm{C}_{60}$ at $330 \mathrm{~K}$. The fitting procedure is complicated because of the presence of very often incomplete peaks, in spite of the frequency window extending over more than 8 decades. As the temperature increases, the relaxation peaks shift to higher frequencies and sweep the frequency window with different speeds characteristic of the relaxation energy of each mode. The fit is quite good and the characteristic relaxation time for the $\alpha$-relaxation process can be extracted. The temperature dependence of the characteristic relaxation times can then be described using the Vogel-Fulcher-Tammann equation [30]:

$$
\tau=\tau_{0} \exp \left(\frac{D T_{0}}{T-T_{0}}\right)
$$

where $\tau_{0}$ is the relaxation time at infinite high temperature, $T_{0}$ is so-called Vogel temperature at which the relaxation time goes to infinity, and $D$ is the parameter related to the fragility of material [31]. A smaller value of $D$ implies steeper temperature dependence of the relaxation time or a more 'fragile' behavior. The changes in the $D$ values for the nanocomposites show that additives such as fullerene $\mathrm{C}_{60}$ enhance the fragility of glass formation related to the molecular packing efficiency of polymer materials, which is indicated physically by softening of the material in the glass state. $E_{\mathrm{VTF}}$ is the characteristic energy for the Vogel-Tammann-Fulcher (VTF) relaxation times and can be found as $E_{\mathrm{VTF}}=D T_{0}$. The relaxation diagrams $-\log \tau_{\max }$ vs. $1 / T$ are curved for the VTF dependences (Fig. 5).

The VFT energies increase with the addition of fullerene $\mathrm{C}_{60}$, but the glass transition temperature does not change. This effect is opposite to the typical result for nanofiller addition, well documented as the 'antiplasticization' phenomenon. In a typical antiplasticization effect, the additives will cause a decrease in the second relaxation time and an increase in the $\alpha$ relaxation time [32]. The addition of fullerene $\mathrm{C}_{60}$, as reported in literature, can either increase or decrease the glass transition temperature of the polymer matrix [33]. In our opinion, this effect is related to the way in which fullerene $\mathrm{C}_{60}$ is incorporated in the polymer matrix (for example, with formation of inclusion complexes in which the $\mathrm{C}_{60}$ molecules are encapsulated within the polymer chain cavity [34]), and the quality of the filler dispersion. In the case of poor dispersion, the aggregates have act as macrofillers, leading to a decrease in the glass transition temperature of the polymer matrix. 
Finally, it is clear that the complex character of the nanoparticle-polymer matrix interactions and better understanding of how nanoparticles can modify the basic polymer properties are of obvious practical, as well as scientific interest. Although the immobilization is a reasonable reinforcing mechanism and its molecular origin is well documented [27-29], a precise prediction or simulation of its extent for various composite systems still represents an intriguing unresolved problem.

\section{Conclusions}

The following conclusions can be drawn from the present study. Fullerene $\mathrm{C}_{60}$, as a filler, improves the mechanical performance of PA6 based composite at low loading. Dielectric spectroscopy was used to investigate the influence of nanoparticles on relaxation processes in polymer matrix. The segmental relaxation processes become faster with the fullerene $\mathrm{C}_{60}$ addition. In contrast, the secondary processes in PA6/ fullerene $\mathrm{C}_{60}$ nanocomposites were observed to slow down with fullerene $\mathrm{C}_{60}$ addition. This indicates an increase in the local 'molecular stiffness'. Therefore, the local 'molecular stiffness' is increased, and the second relaxation times are phenomenologically linked to the mechanical properties, which may explain the increased Young's moduli of nanocomposites with fullerene $\mathrm{C}_{60}$ additives. These observations suggest that nanoparticles can have a qualitatively different effect on matrix polymer dynamics at different length scales, and caution must be taken when comparing changes in the dynamics associated with different relaxation processes.

\section{References}

[1] Bijwe J., Logani C.M., Tewari U.S. Influence of fillers and fiber reinforcement on abrasive wear resistance of some polymeric composites. Wear, 1990, 138, P. 77-92.

[2] Treacy M.M.J., Ebesen T.W., Gibson J.M. Nanoparticles as reinforced agents. Nature, 1996, 381, P. $678-680$.

[3] Strobl G. The Physics of Polymers. Springer, Berlin, 2007, 450 p.

[4] Prato M. [60] Fullerene chemistry for material science applications. J. Mater. Chem., 1997, 7, P. $1097-1109$.

[5] Schaefer D.W., Justice R.S. How nano are nanocomposites. Macromolecules, 2007, 40, P. 8501-8517.

[6] Spitalsky Z., Tasis D., Papagelis K., Galiotis K. Carbon nanotube-polymer composites: Chemistry, processing, mechanical and electrical properties. Prog. Polym. Sci., 2010, 35, P. 357-401.

[7] Adachi K,, Kotaka T. Dielectric normal mode relaxation. Progr. Polym. Sci., 1993, 18, P. 585-622.

[8] Zuev V.V., Ivanova Y.G. Mechanical and electrical properties of polyamide- 6 based nanocomposites reinforced by fulleroid fillers. Polym. Eng. Sci., 2012, 52, P. 1206-1211.

[9] Kawauchi M., Kawauchi T., Takeichi T. Solubilization of [60]Fullerene Owing to Inclusion Complex Formation between Syndiotactic Poly(methyl methacrylate) and the Fullerenes in Polar Solvents. Macromolecules, 2009, 42, P. 6136-6142.

[10] Zuev V.V., Shlikov A.V. Polyamide 12/ fullerene $\mathrm{C}_{60}$ composites: investigation on their mechanical and dielectric properties. J. Polym. Research, 2012, 19, P. 1-6 (9925).

[11] Moniruzzaman M., Winey K.I. Polymer nanocomposites containing carbon nanotubes. Macromolecules, 2006, 39, P. 5194-5205.

[12] Russo P., Acierno D., Di Maio L., Demma G. Thermal and mechanical characterization of films from nylon 6/EVOH blends. Eur. Polym. J., 1999, 35 (7), P. 1261-1268.

[13] Naffakh M., Diaz-Pascual A.M., et al. Opportunities and challenges in the use of inorganic fullerene-like nanoparticles to produce advanced polymer nanocomposites. Prog. Polym. Sci., 2013, 38, P. 1163-1231.

[14] Goitisolo I., Eguiazabal J.I., Nazabal J. Effects of reprocessing on the structure and properties of polyamide 6 nanocomposites. Polym. Deg. Stab., 2008, 93, P. 1747-1752.

[15] Lincoln D.M., Vaia R.A., Wang Z.-G., Hsiao B.S. Secondary structure and elevated temperature crystallite morphology of nylon-6/ layered silicate nanocomposites. Polymer, 2001, 42, P. 1621-1629.

[16] Liu H., Brinson L.C. Reinforcing efficiency of nanoparticles: a simple comparison for nanocomposites. Compos. Sci. Tech., 2008, 68, P. 1502-1512.

[17] Liu T., Phang I.Y., et al. Morphology and mechanical properties of multywalled carbon nanotubes reinforced nylon-6 composites. Macromolecules, 2004, 37, P. 7214-7222. 
[18] Wu T.M., Liao C.S. Polymorphism in nylon 6/clay nanocomposites. Macromo. Chem. Phys., 2000, 201, P. 2820-25.

[19] Ito M., Mituochi K., Kanamoto T. Effects of crystalline forms on the deformation behaviour of nylon-6. Polymer, 1998, 39, P. 4593-4598.

[20] Mesbah A., Zari F., et al. Experimental characterization and modeling stiffness of polymer/clay nanocomposites within a hierarchical multiscale framework. J. Appl. Polym. Sci., 2009, 114, P. 3274-91.

[21] Avakian P., Matheson R.R., Starkweather H.W. Implications of dielectric response for the mechanism of changes in oxygen transport due to traces of moisture in amorphous nylons. Macromolecules, 1991, 24, P. 4698-4700.

[22] Laredo E., Grimau M., Sanchez F., Bello A. Water Absorption Effect on the Dynamic Properties of Nylon-6 by Dielectric Spectroscopy. Macromolecules, 2003, 36, P. 9840-9850.

[23] Laredo E., Hernandez M.C. Moisture effect on the low- and high-temperature dielectric relaxations in nylon-6. J. Polym. Sci. B, 1997, 35, P. 2879-2888.

[24] Frank B., Frubing P., Pissis P. Water sorption and thermally stimulated depolarization currents in nylon-6. J. Polym. Sci. B, 1996, 34, P. 1853-1860.

[25] Havriliak S., Negami S.. A complex plane analysis of $\alpha$-dispersions in some polymer systems. J. Polym. Sci. $C, 1966,14$, P. 99-117.

[26] Havriliak S., Negami S. A complex plane representation of dielectric and mechanical relaxation processes in some polymers. Polymer, 1967, 8, P. 161-210.

[27] Allegra G., Raos G., Vacatello M. Theories and simulations of polymer based nanocomposites: from chain statistics to reinforcement. Prog. Polym. Sci., 2008, 33, P. 683-731.

[28] Reynaud E., Jouen T., et al. Nanofillers in polymeric matrix: astudy on silica reinforced PA6. Polymer, 2001, 42, P. 8759-8768.

[29] P. Ramasundaram S., Kim K.J. In-situ synthesis and characterization of polyamide 6/POSS nanocomposites. Macromol. Symp., 2007, 249-250, P. 295-302.

[30] Kremer F., Schonhals A. Broadband dielectric spectroscopy. Springer, New York, 2003, 430 p.

[31] Angell C.A., Ngai K.L., et al. Relaxation in glassforming liquids and amorphous solids. J. Appl. Phys., 2000, 88, P. 3113.

[32] Pikhurov D.V., Zuev V.V. The effect of fullerene $\mathrm{C}_{60}$ on the mechanical and dielectric behaviour of epoxy resins at low loading. Nanosystems: Phys., Chem., Math., 2013, 4 (6), P. 834-843.

[33] Wang C., Guo Z.-X. et al. Polymers containing fullerene or carbon nanotube structures. Prog. Polym. Sci., 2004, 29, P. 1079-1141.

[34] Zuev V.V. Polymer nanocomposites containing fullerene $\mathrm{C}_{60}$ nanofillers. Macromol. Symp., 2011, 301, P. 157161 . 